\title{
Milk-derived ribonuclease 5 preparations induce myogenic differentiation in vitro and muscle growth in vivo
}

\author{
Matthew I. Knight, ${ }^{*} \dagger$ Angus M. Tester, ${ }^{*}$ Matthew B. McDonagh, ${ }^{*} \dagger$ Andrew Brown,‡ Jeremy Cottrell,, \\ Jianghui Wang, ${ }^{*}$ Peter Hobman, $\ddagger$ and Benjamin G. Cocks ${ }^{*}{ }^{1}$ \\ *Biosciences Research, Department of Environment and Primary Industries, AgriBio, 5 Ring Road, Bundoora, Victoria, Australia, 3083 \\ †Agriculture Research and Development, Department of Environment and Primary Industries, 915 Mt Napier Road, Hamilton, Victoria, Australia, \\ 3300 \\ ‡Murray Goulburn Co-operative Limited, 140 Dawson Street, Brunswick, Victoria, Australia, 3056 \\ $\S$ La Trobe University, Kingsbury Drive, Bundoora, Victoria, Australia, 3086
}

\section{ABSTRACT}

Ribonuclease 5, also known as angiogenin, is a stable and abundant ribonuclease in milk whey protein, which is able to regulate several cellular functions, including capillary formation, neuron survival, and epithelial cell growth. Ribonuclease 5 is important for protein synthesis directly stimulating rRNA synthesis in the nucleolus. Here, we show that biologically active RNase5 can be purified from bovine milk. Furthermore, we show that milk-derived RNase5 directly stimulates muscle cell differentiation in vitro, inducing $\mathrm{C} 2 \mathrm{C} 12$ cell differentiation and myogenesis. When supplemented into the diet of healthy adult mice, milk-derived RNase5 preparations promoted muscle weight gain and grip strength. Collectively, these data indicate that milk-derived RNase 5 preparations exhibit a novel role in skeletal muscle cell function.

Key words: growth factor, RNase5, myogenic differentiation, muscle growth

\section{INTRODUCTION}

Milk provides a rich source of nutrients, immune factors, and bioactive proteins for the growing newborn and is also known to assist in muscle accretion (Burrin et al., 1992; Pennings et al., 2011). Numerous studies have shown that milk whey protein supplementation can promote an increase in the size of muscles subjected to mechanical stimulus, such as physical activity or exercise (Burke et al., 2001; Anderson and Behm, 2005). This anabolic effect has been attributed to either branched-chain amino acids, especially leucine (Phillips et al., 2009), or growth factors. Although the oral consumption of IGF has been implicated, no scientific evidence exists to substantiate its efficacy (Belford et al., 1995). In addition the oral consumption of whey

Received January 5, 2014

Accepted June 5, 2014.

${ }^{1}$ Corresponding author: Ben.Cocks@depi.vic.gov.au protein supplementation also has been shown to improve serum protein balance after resistance exercise (Tipton et al., 2007) and improve muscle satellite cell regulation (Olsen et al., 2006).

Bovine milk whey protein comprises several major proteins such as $\beta$-LG (rich in branched-chain amino acids), $\alpha-\mathrm{LA}$, and BSA as well as relatively low concentrations of a group of basic proteins. The most abundant of these are lactoferrin and lactoperoxidase. Several growth factors are also present in the basic protein fraction, which, because of their high isoelectric points, can be readily separated from the bulk of the other basic proteins and further purified, using cation-exchange chromatography. Such fractions are frequently referred to as growth factor extract (Dyer et al., 2008) and contain IGF (IGF-1 and IGF-2), platelet-derived growth factor, fibroblast growth factor (FGF; Rogers et al., 1995), and transforming growth factor- $\beta$ (Rogers et al., 1996). Numerous preparations of milk whey fractions are commercially available and have the potential to prevent and promote muscle growth (Dyer et al., 2008; Pennings et al., 2011).

An initial objective of this study was to characterize a commercially available bioactive milk whey preparation and identify the active component(s) that contribute to the beneficial effects of oral consumption on muscle growth and strength (Dyer et al., 2008). Traditional chromatographic techniques were used as well SDS-PAGE to analyze the protein composition and proteomic profile. Ribonuclease 5 was identified and characterized as an abundant and stable protein. Several preparations of RNase 5 estimated to contain 10,50 , and $95 \%$ RNase5 were purified from milk whey protein and their biological activity investigated in in vitro and in vivo models of myogenic differentiation and muscle growth.

\section{MATERIALS AND METHODS}

Recombinant proteins used in proliferation and myogenesis studies were sourced from R\&D Systems 
Inc. (Minneapolis, MN), unless otherwise stated. Milk whey preparations (RNase5-10, RNase5-50, and RNase5-95) were obtained by successive purification from milk whey protein. The $-10,-50$, and -95 refer to intact RNase 5 protein content in the preparation being 10, 50, and $95 \%$, respectively.

\section{Extraction Procedure Used to Enrich for RNase 5 from Milk Whey}

The bovine RNase5 extract referred to as RNase5-10 was purified by passing skim milk $(3,300 \mathrm{~L})$ through a column filled with SP resin (GE Life Sciences, Foster City, CA; Brown et al., 2010), rinsing with 180 L of water, and then eluting with $180 \mathrm{~L}$ of $2.5 \% \mathrm{NaCl}$. A semipurified milk RNase5 (RNase5-50) was isolated from RNase 5-10 by applying $1 \mathrm{~kg}$ of RNase5-10 solution to a column filled with SP resin (GE Life Sciences), rinsing with $360 \mathrm{~L}$ of $2.0 \% \mathrm{NaCl}$, and then eluting with 180 $\mathrm{L}$ of $2.5 \% \mathrm{NaCl}$. The RNase5-10 and RNase5-50 were desalted by UF with $10-\mathrm{kDa}$ membranes (Brown et al., 2010). The RNase5-95 was purified from RNase5-50 solution using cation-exchange HPLC with a linear gradient of $\mathrm{NaCl}$ in $50 \mathrm{~m} M$ phosphate buffer (pH 7.0), followed by size exclusion chromatography using Mono $\mathrm{S}$ 10/100 GL and Sephacryl S-100 HR columns (GE Life Sciences). The RNase5-10, RNase5-50, and RNase5-95 were freeze-dried and stored at $4^{\circ} \mathrm{C}$.

To quantify the major whey proteins (lactoperoxidase, lactoferrin, and RNase5) present in each of the RNase5-10, -50, and -95 preparations, the respective protein samples were resuspended at $5 \mathrm{mg} / \mathrm{mL}$ in 50 $\mathrm{m} M$ sodium phosphate containing $5 \%$ acetonitrile $(\mathrm{pH}$ 7.0). Each sample was then separated on a Mono S 5/50 GL column (GE Life Sciences), pre- equilibrated with buffer A [50 $\mathrm{m} M$ sodium phosphate containing $5 \%$ (vol/vol) acetonitrile, $\mathrm{pH}$ 7.0]. One hundred microliters of the $5 \mathrm{mg} / \mathrm{mL}$ solution was loaded onto the column in buffer $\mathrm{A}$ and a linear gradient was applied to increase to $100 \%$ buffer B (50 $\mathrm{mM}$ sodium phosphate and $1 M$ $\mathrm{NaCl}, \mathrm{pH} 7.0$ ) in 3.5 min after injection and continued at $100 \%$ buffer B for the remainder of the Mono S 5/50 GL column chromatography. The lactoferrin and lactoperoxidase concentrations in the eluate were determined using absorbance spectrophotometry at 280 $\mathrm{nm}$ for lactoferrin and lactoperoxidase and $220 \mathrm{~nm}$ for RNase5. The amount of IgA present in the RNase5-10, -50 , and -95 protein preparations was determined using a Bovine IgA ELISA Quantitation Kit (Bethyl Laboratories Inc., Montgomery, TX) according to the manufacturer's instructions. The amount of IgG present in the RNase5-10, -50, and -95 protein preparations was determined by protein $\mathrm{G}$ affinity chromatography according to Abernethy et al. (2010). The remaining protein content was characterized as other whey proteins.

Confirmation of the enrichment procedure used to purify the RNase5-10, -50, and -95 preparations was performed by SDS-PAGE under reducing conditions on NuPAGE precast gradient gel (4-12\%; Invitrogen Corp., Grand Island, NY; Laemmli, 1970). The protein gel was stained with SYPRO Ruby (Invitrogen Corp.) and imaged using a cooled scanning charge-coupled device (CCD) camera (ProXPRESS; PerkinElmer Life Sciences, Waltham, MA).

\section{RNase Activity Assay}

The RNase activity assay was performed using the RNaseAlert QC system from Ambion (Invitrogen Corp.) according to the manufacturer's instructions. Ribonuclease activity was detected by a cleavable fluorescent-labeled RNase substrate and recorded on a Synergy 2 plate reader (BioTek Instruments Inc., Winooski, VT).

\section{In Vitro Matrigel Angiogenesis Assay}

To confirm that the enriched preparations of RNase5 were biologically active, in vitro Matrigel angiogenesis assays were performed as described by Ponce (2001). Briefly, 6-well plates were coated with ice-cold Matrigel (BD Biosciences, San Jose, CA), which was allowed to polymerize at room temperature for about $30 \mathrm{~min}$. Thereafter, human umbilical vein endothelial cells (HUVEC; $5 \times 10^{4}$ cells $/ \mathrm{mL}$ ) that had been pretreated with $100 \mathrm{ng} / \mathrm{mL}$ of RNase $5-10$ or recombinant human RNase 5 , or $5 \mathrm{ng} / \mathrm{mL}$ of vascular endothelial growth factor (VEGF) 165 (positive control; R\&D Systems Inc.) for up to $5 \mathrm{~d}$ were seeded onto the Matrigel. Cells were cultured overnight in Iscove's modified Dulbecco's medium, supplemented with $100 \mathrm{IU}$ of penicillin/mL, $100 \mu \mathrm{g}$ of streptomycin $/ \mathrm{mL}, 1 \%$ (vol/vol) fetal calf serum, and $5 \mathrm{ng}$ of basic $\mathrm{FGF} / \mathrm{mL}$ in the presence or absence of various RNase5-enriched milk preparations or VEGF. Tube formation was assessed every $12 \mathrm{~h}$ and bright field images were captured.

\section{C2C12 Myogenesis Assay}

The $\mathrm{C} 2 \mathrm{C} 12$ cell line is an immortal line of mouse skeletal myoblasts originally derived from satellite cells from the thigh muscle of a 2-mo-old female C3H mouse donor (Yaffe and Saxel, 1977). The C2C12 cells were used between passages 25 and 30 and seeded in 6-well plates at $2.5 \times 10^{5}$ cells $/ \mathrm{mL}$, and allowed to attach overnight; $\mathrm{C} 2 \mathrm{C} 12$ myogenesis was then induced through changing the medium from growth medium (DMEM 
containing $10 \%$ fetal bovine serum) to differentiation medium (DMEM containing 2\% horse serum), supplemented with one of the following experimental treatments: control (differentiation medium alone), $200 \mathrm{ng}$ of IGF-1/mL (positive control), $10 \mu \mathrm{g}$ of RNase5-50/ $\mathrm{mL}, 10 \mu \mathrm{g}$ of RNase $5-95 / \mathrm{mL}$, or recombinant human RNase $5(1 \mu \mathrm{g} / \mathrm{mL})$. The enzyme creatine kinase $(\mathbf{C K})$ was used as a marker of $\mathrm{C} 2 \mathrm{C} 12$ myogenesis and activity was quantified by CK activity (CK-NAC; Thermo Fisher, Fair Lawn, NJ) in accordance with the manufacturer's instructions. Immunohistochemistry was used to confirm myogenic differentiation by staining with myosin heavy chain (mouse anti-myosin antibody; Invitrogen Corp.). The presence of myosin heavy chain was visualized using confocal fluorescence microscopy (model number FV10i; Olympus America Inc., Center Valley, PA).

\section{Mouse Supplementation Studies}

All experiments were carried out on 8-wk-old (adult) male $\mathrm{C} 57 \mathrm{Bl} / 10$ mice obtained from the Animal Resource Centre (Murdoch, WA). They were housed on a 12-h light/dark cycle, under standard conditions, with free access to food and drinking water. All animal experiments were conducted in strict accordance with the guidelines of the National Health and Medical Research Council Code of practice for the care and use of animals for scientific purposes (2004) and the Animal Welfare act of Western Australia (2002) and were approved by the Animal Ethics committee at the University of Western Australia (Perth, Australia; RA-3-100-679).

In 3 separate experiments, mice were fed a control diet consisting of the American Institute of Nutrition (AIN)-recommended AIN93G rodent growth diet (Reeves et al., 1993) or AIN93G containing $166 \mu \mathrm{g}$ of RNase $5-10 / \mathrm{g}$ of feed (diet 1), $17 \mu \mathrm{g}$ of RNase $5-50 / \mathrm{g}$ of feed (diet 2), or $166 \mu \mathrm{g}$ of RNase5-50/g feed (diet 3). All diets were prepared by Specialty Feeds Pty Ltd. (Glen Forrest, WA, Australia). Experiments were conducted on sedentary mice for 1 or 4 mo duration or mice exercising voluntarily on a wheel for 1 mo duration (28 d). Each treatment group contained 8 animals. For exercising mice, a metal mouse wheel (300 $\mathrm{mm}$ in diameter) was placed inside the cage and the total distance voluntarily run by each individual mouse over the experiment was recorded in kilometers using an attached bicycle pedometer (Hodgetts et al., 2006; Radley and Grounds, 2006; Radley et al., 2008). Mice were monitored for BW (g) weekly. Muscle grip strength was measured weekly using a Chatillon Digital Force Gauge (DFE-002; John Chatillon \& Sons Inc., Largo, FL). In brief, the mouse was placed on the front of the triangle bar (attached to a force transducer) and pulled gently until release. Each mouse underwent 5 consecutive grip-strength trials; the grip-strength value for each mouse was recorded as the average of the 3 best efforts and grip force (Hz; RadleyCrabb et al., 2012). At the completion of the each of the 3 individual feeding trials, all mice were anaesthetized with $1.5 \%$ (vol/vol) Rodia halothane (Merial Australia, North Ryde, NSW, Australia), $\mathrm{N}_{2} \mathrm{O}$, and $\mathrm{O}_{2}$, before being euthanized by cervical dislocation. The entire musculus tibialis anterior (TA), musculus gastrocnemius (i.e., gastrocnemius), musculus quadriceps femoris (i.e., quadriceps), and epididymal fat pad were dissected and weighed.

\section{Statistical Analysis}

The $\mathrm{C} 2 \mathrm{C} 12$ myogenesis data were analyzed using an ANOVA for unbalanced designs for treatment by time with a block on experimental replicate. For mouse supplementation studies, all parameters were analyzed by ANOVA (for unbalanced designs, where appropriate) for the effects of treatment. For treatments that were statistically significance, a 2-tailed Student's $t$ test was performed post-hoc to determine the effect of treatment diet versus the nonsupplemented control diet. All ANOVA statistical analyses were performed in GenStat software (13th ed.; VSN International Ltd., Hemel Hempstead, UK) and all Student's $t$-tests were performed in Microsoft Excel software (version 2003; Microsoft Corp., Redmond, WA).

\section{RESULTS}

\section{Preparations of RNase5 from Milk Whey}

Enrichment of RNase5 protein from whole milk was observed by SDS-PAGE (Figure 1). Densitometric analysis demonstrated that the RNase5 content increased from approximately $10 \%$ of the milk whey protein content in the RNase5-10 preparation to approximately $50 \%$ of the milk whey protein content in the RNase $5-50$ preparation to $>95 \%$ in the RNase $5-95$ preparation due to the removal of the major contaminating proteins.

\section{Protein Composition of RNase5-10, -50, and -95}

The protein composition of RNase5-10, RNase5-50, and RNase5-95 is shown in Table 1. The RNase5-10 preparation contained numerous proteins that were consistent with proteins known to be in milk whey, the most predominant protein species being lactoferrin and lactoperoxidase. The amount of RNase 5 protein present in the RNase5-10 protein preparation varied between purification batches and ranged from 8 to 11\% (Table 1; Figure 1). 


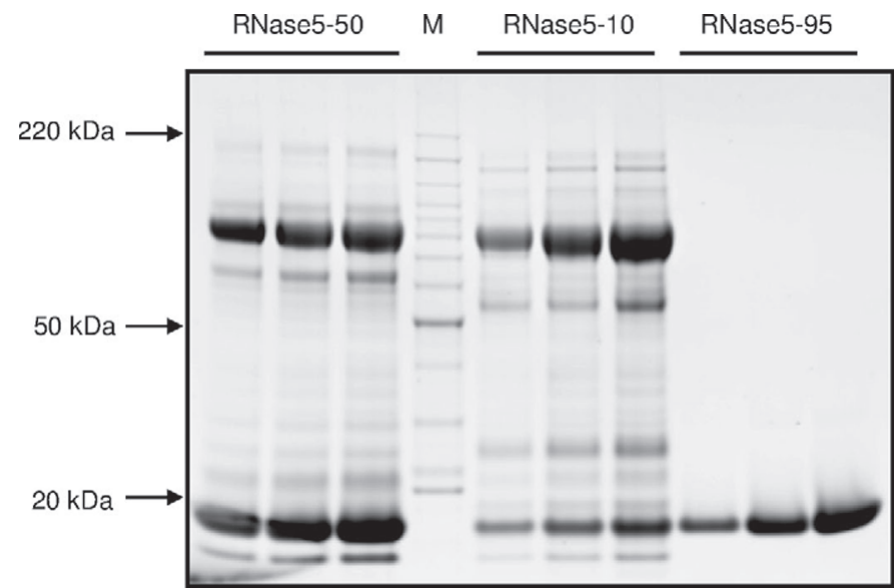

Figure 1. Sodium dodecyl sulfate PAGE of several different milkenriched preparations of bovine RNase5. Lane M contains BenchMark protein ladder (Invitrogen Corp., Grand Island, NY).

\section{Determination of Milk RNase5 Biological Activity}

Ribonuclease activity and in vitro Matrigel angiogenesis assays were performed to confirm whether the RNase5 derived from milk whey was biologically active. It was found that the RNase activity increased as the concentration of RNase increased with 11.8 relative fluorescence units (RFU)/ng in RNase5-10 to 148 $\mathrm{RFU} / \mathrm{ng}$ in RNase5-50 and $446 \mathrm{RFU} / \mathrm{ng}$ for the highly purified RNase5-95 extracts. The increase in RNase activity in the milk whey extracts was consistent with the increases in RNase5 concentration observed in SDSPAGE (Figure 1).

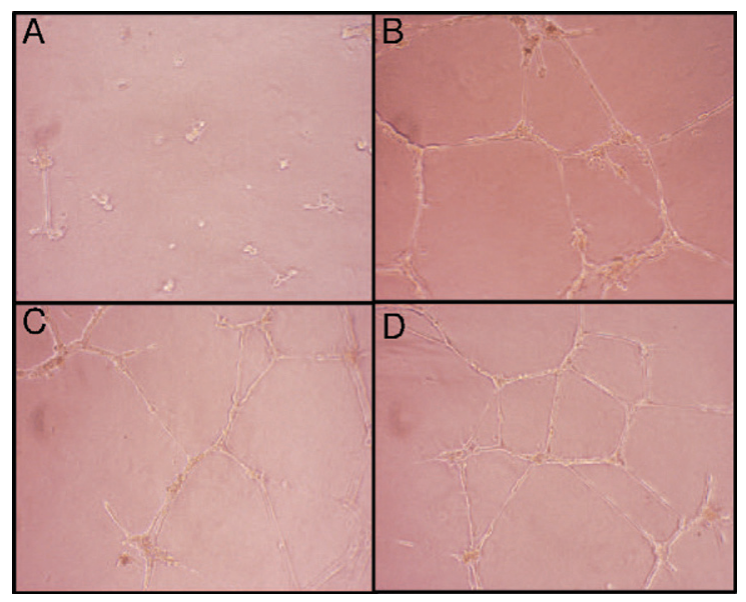

Figure 2. Endothelial tube formation assays were performed in cultured human umbilical vein endothelial cells (HUVEC) untreated (A) or treated with $100 \mathrm{ng} / \mathrm{mL}$ of RNase 5 with $10 \%$ protein content (RNase5-10; B), $5 \mathrm{ng} / \mathrm{mL}$ of vascular endothelial growth factor (VEGF) 165 (C; positive control), or $100 \mathrm{ng} / \mathrm{mL}$ of recombinant human RNase5 ( D; positive control). Endothelial tube formation was visualized under an inverted light microscope at $4 \times$ magnification. Color version available in the online PDF.
.

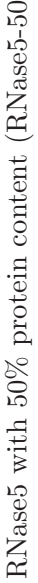

官

望

$\stackrel{\Xi}{\exists}$

苛

:

ถ̊ํำ

곤

(2)

究

$\ddot{8}$

望

世

.

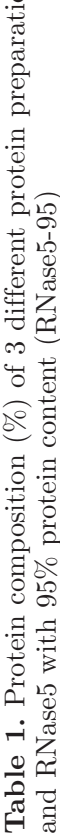

궁

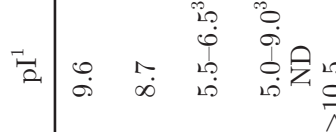

․ $\stackrel{\text { กิ }}{7}$

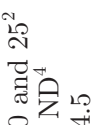

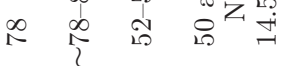

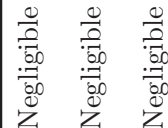

ㄷำ 20

$\circ \therefore \frac{0}{6}$.

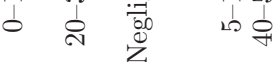

우 웅 0 뜩

위 위 $\infty \quad \infty$ 


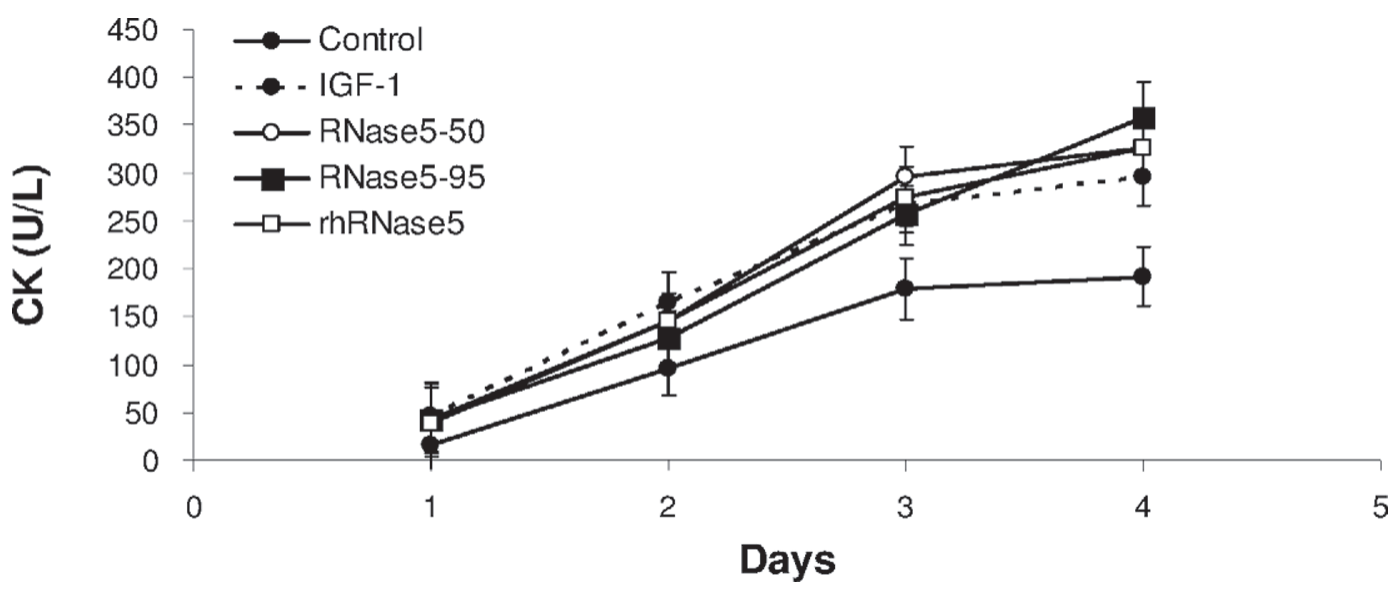

Figure 3. Addition of milk whey-enriched RNase5 preparations to differentiating C2C12 myoblasts resulted in increased creatine kinase (CK) activity, an indicator of myotube formation (ANOVA: $P<0.05$ for all treatment groups compared with control group). The C2C12 myoblasts were differentiated in $2 \%$ horse serum (control) and $2 \%$ horse serum with one of the following treatments: $10 \mu \mathrm{g} / \mathrm{mL}$ of RNase 5 with $50 \%$ protein content (RNase5-50), $10 \mu \mathrm{g} / \mathrm{mL}$ of RNase5 with $95 \%$ protein content (RNase5-95), $1 \mu \mathrm{g} / \mathrm{mL}$ of recombinant human RNase5 (rhRNase5), or $200 \mathrm{ng} / \mathrm{mL}$ of IGF-1 ( $\mathrm{n}=3-5$ per time point). Error bars represent the standard error of the mean of 5 different cell passages, $\mathrm{n}=3$ to 5 per cell passage.

The in vitro Matrigel angiogenesis assay replicates the early stages of angiogenesis where endothelial cells migrate, align, and fuse into tubular networks. Representative bright field images are shown in Figure 2. Tube formation was observed when HUVEC were incubated with RNase5-10 (100 ng/mL) along with the positive controls [VEGF $165(5 \mathrm{ng} / \mathrm{mL})$ and rhRNase 5 $(100 \mathrm{ng} / \mathrm{mL})]$, whereas no tubes were formed in the untreated controls. These findings demonstrate that RNase5-10 has angiogenic properties, likely due to the presence of biologically active RNase 5 .

\section{RNase5 Stimulates Myogenesis In Vitro}

The ability of RNase 5 to mediate myogenesis in vitro was examined using differentiating $\mathrm{C} 2 \mathrm{C} 12$ myoblasts.
Myogenesis was evaluated by measuring CK activity. RNase5-50 and RNase5-95 increased CK activity in differentiating $\mathrm{C} 2 \mathrm{C} 12$ myoblasts compared with untreated differentiating $\mathrm{C} 2 \mathrm{C} 12$ myoblasts (Figure 3). Differentiating $\mathrm{C} 2 \mathrm{C} 12$ myoblasts were also treated with 2 different positive controls - rhRNase $5(1 \mu \mathrm{g} / \mathrm{ml})$ and IGF-1 $(200 \mathrm{ng} / \mathrm{ml})$. Both positive controls also showed increases in CK activity when compared with untreated differentiating $\mathrm{C} 2 \mathrm{C} 12$ myoblasts. These results demonstrate enhanced myogenesis in vitro and indicate a novel activity for RNase5 in skeletal muscle development. Myosin heavy chain staining of differentiating $\mathrm{C} 2 \mathrm{C} 12$ myoblasts revealed that cells treated with milk whey preparations containing RNase5 (i.e., RNase5-50) had visibly more myosin heavy chain content than untreated control C2C12 cells (Figure 4). Studies exam-
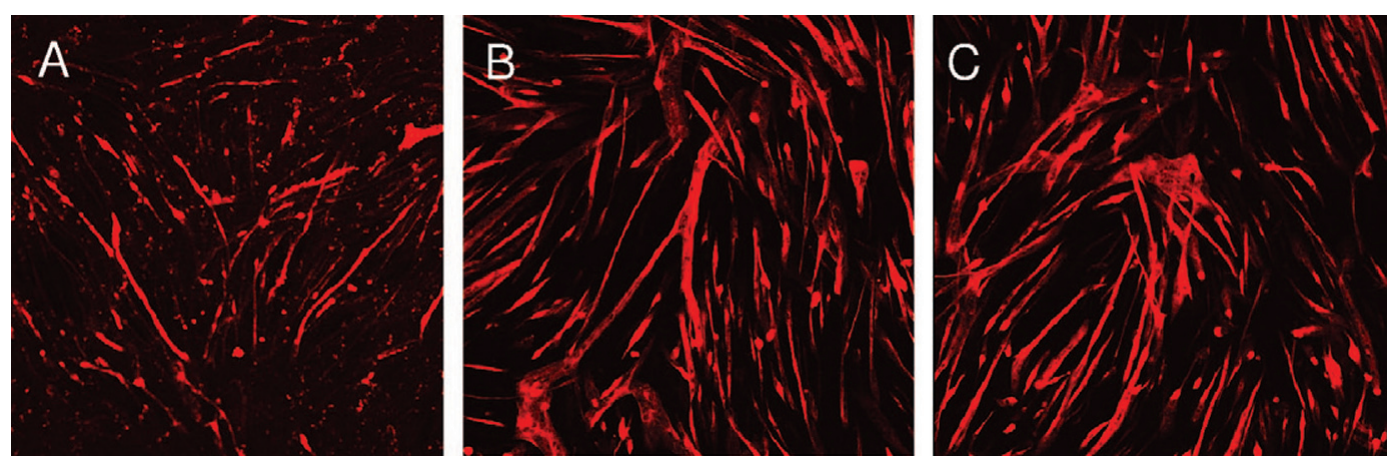

Figure 4. Treatment of $\mathrm{C} 2 \mathrm{C} 12$ myoblasts with RNase5-enriched milk whey isolates promotes myotube formation. The C2C12 myoblasts were treated with $2 \%$ horse serum (A) and $2 \%$ horse serum treated with either $10 \mu \mathrm{g} / \mathrm{mL}$ of RNase 5 with $50 \%$ protein content (RNase5-50; B) or 10 $\mu \mathrm{g} / \mathrm{mL}$ of RNase 5 with $95 \%$ protein content (RNase5-95; C). Myoblasts were allowed to differentiate into myotubes for $4 \mathrm{~d}$. After $4 \mathrm{~d}$ of differentiation, the $\mathrm{C} 2 \mathrm{C} 12$ cells were fixed with $4 \%$ paraformaldehyde and the presence of myosin heavy chain was determined by immunohistochemistry and imaged using an Olympus confocal microscope (Olympus America Inc., Center Valley, PA). Color version available in the online PDF. 
ining cell proliferation demonstrated that all RNase5 preparations had minor, but significant effects on C2C12 cell proliferation as determined by water-soluble tetrazolium salt (WST)-1 assay (data not shown).

\section{Effect of RNase5-10 and RNase5-50 on Muscle Weight Gain in C57BI/10 Mice}

The influence of RNase5 on adult mouse muscle growth was analyzed within 3 separate experiments. Mice were fed 1 of 4 diets: the control mouse chow (AIN93G) or AIN93G supplemented with (1) $166 \mu \mathrm{g}$ of RNase5-10/g feed (diet 1), (2) $17 \mu \mathrm{g}$ of RNase5-50/g feed (diet 2), or (3) $166 \mu \mathrm{g}$ of RNase5-50/g feed (diet 3 ). In the first and second experiments, sedentary mice were treated for a period of 1 mo or 4 mo, respectively, and in the third experiment, mice were allowed to exercise voluntarily for a period of 1 mo.

The diets did not significantly affect the quadriceps muscle weights of sedentary mice in the 1-mo feeding cohort $(P=0.18$; Figure 5A). However, after 4 mo of supplementation, the quadriceps muscle weights of sedentary mice fed diet 2 were significantly greater than those mice fed the control diet $(P<0.05$; Figure 5B).

When mice were allowed to exercise voluntarily for 1 mo, both diet 1 and diet 2 significantly increased quadriceps muscle weights by over $55 \%(P \leq 0.001)$ and $35 \%$ $(P=0.044)$, respectively, compared with the control diet (Figure 5C). Unlike the control mice cohort, mice on diet 1 did not gain weight in the study period and, as a result, weighed significantly less than the control mice cohort (Supplementary Figure S1; http://dx.doi. org/10.3168/jds.2014-7901). As these mice did not have lower feed intakes or lower levels of epididymal fat, it is unlikely that this reduction in BW was due to nutritional factors. Mice fed diet 1 also exercised approximately $20 \%$ more than the control treatment group (control: $6.4 \mathrm{~km}$ vs. diet 1: $7.8 \mathrm{~km}$ average daily distance run; $P=0.057$ ), whereas no differences were observed with diets 2 and 3 (Figure 6). Additionally, functional increases in grip strength of approximately $20 \%$ were measured in all experimental diets (Figure 7).

Other muscle weights (i.e., TA and gastrocnemius) were not influenced by any experimental diet and, likewise, abdominal fat was largely unaffected by diet, with an exception for a trend for increased fat in sedentary mice supplemented with diet 3 for 1 mo $(P=0.094)$. Supplementation with RNase5-10 (diet 1) did not influence any of the tissue weights.

\section{DISCUSSION}

Milk is an important source of nutrients, immune factors, and bioactive proteins for the developing neonate.

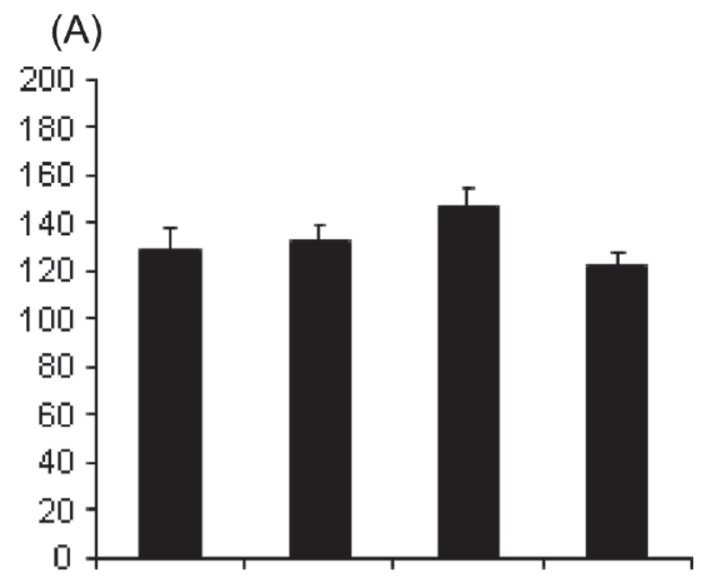

(B)

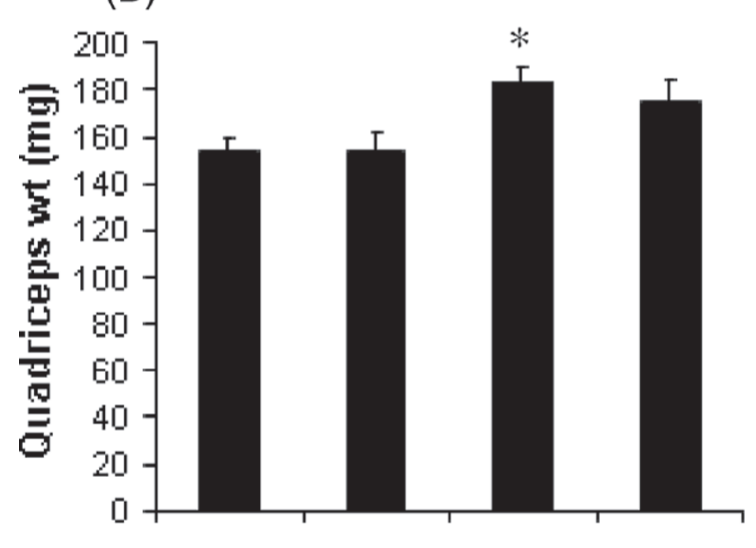

(C)

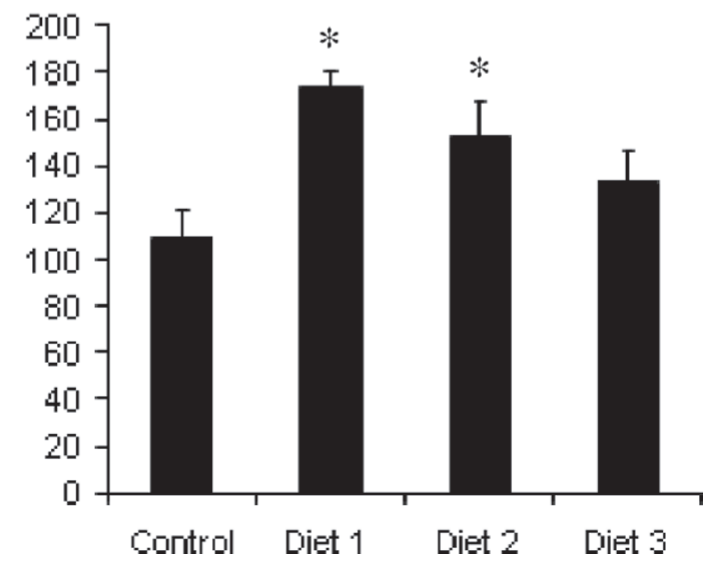

Figure 5. Increase in musculus quadriceps femoris weight (mg) from mice supplemented with milk whey-enriched RNase5. The mice were fed for a period of $1 \mathrm{mo}(\mathrm{A})$ or $4 \mathrm{mo}(\mathrm{B})$ without exercise or $1 \mathrm{mo}$ (C) with voluntary exercise. The 4 diets used in this study were the American Institute of Nutrition (AIN)-recommended AIN93G rodent diet (control diet) or AIN93G supplemented with RNase5 with $10 \%$ protein content (RNase5-10) at $166 \mu \mathrm{g} / \mathrm{g}$ of feed (diet 1), RNase5 with $50 \%$ protein content (RNase5-50) at $17 \mu \mathrm{g} / \mathrm{g}$ of feed (diet 2), or RNase $5-50$ at $166 \mu \mathrm{g} / \mathrm{g}$ of feed (diet 3 ). * represents statistically significant differences in mice fed the experimental diets compared with mice fed the control diet (Student's t-test: $P<0.05 ; \mathrm{n}=8$ ). Error bars represent the standard error of the mean for each diet. 


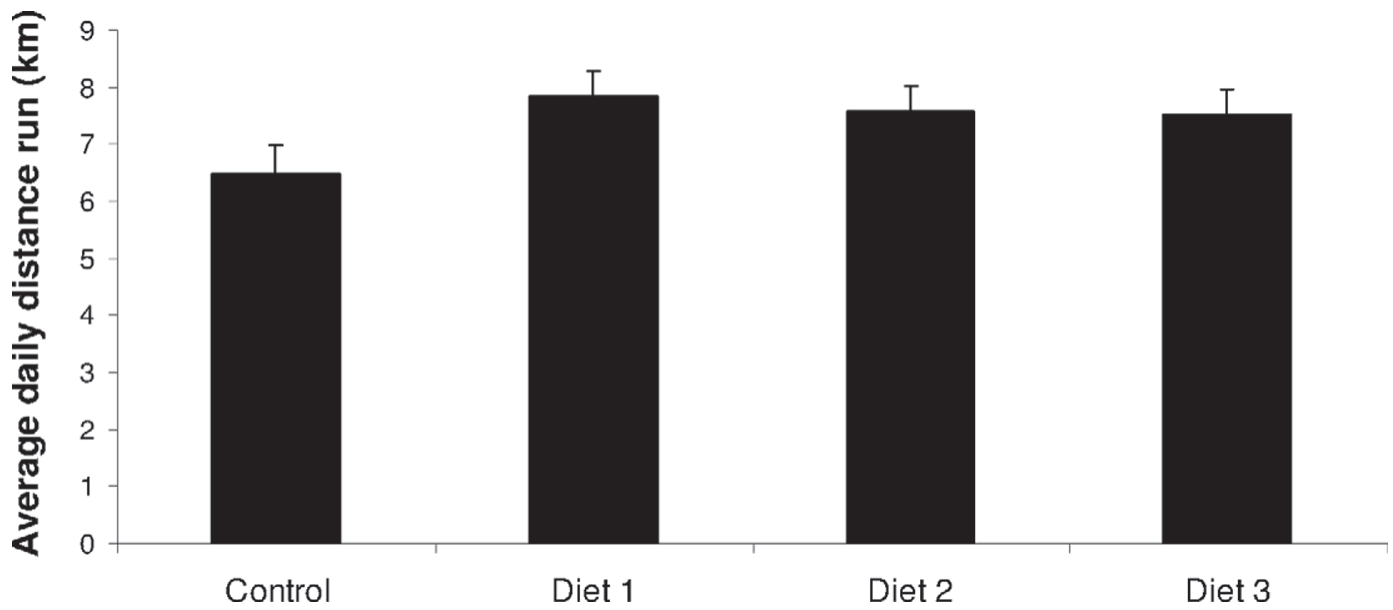

Figure 6. A tendency existed for mice fed diet 1 to run further over the course of the experiment compared with control mice (Student's $t$ test: $P=0.057)$. Mice fed diet 2 and diet 3 containing various amounts of RNase 5 with $50 \%$ protein content (RNase $5-50)$ were not significantly different from control mice $(P>0.10)$. Error bars represent the standard error of the mean for each diet.

However, the role of the nonnutritive bioactive protein component is the least understood. The mechanism by which milk bioactive proteins mediate their effects is not clear, but nonnutritive factors in milk stimulate protein synthesis in the vital organs, skeletal muscle, and myofibrillar proteins (Burrin et al., 1997; Fiorotto et al., 2000). Whey protein is a nutrient source derived from milk and contains a group of basic proteins, which, when extracted, are commonly referred to as the growth factor extract because of the presence of higher concentrations of growth factors and their ability to promote muscle growth and repair in vivo (Burke et al., 2001; Anderson and Behm, 2005; Dyer et al., 2008). However, mechanical stimulus in the form of exercise or physical activity is required for muscle growth to occur.

The initial objective of this study was to purify and identify biologically active proteins derived from basic milk whey protein and characterize their effect on muscle growth. Ribonuclease 5 was identified and purified to produce 3 RNase5 preparations designated RNase5-10, -50 , and -95 signify the purity of the RNase5 $(10,50$, and $95 \%$, respectfully). The HUVEC assays confirmed

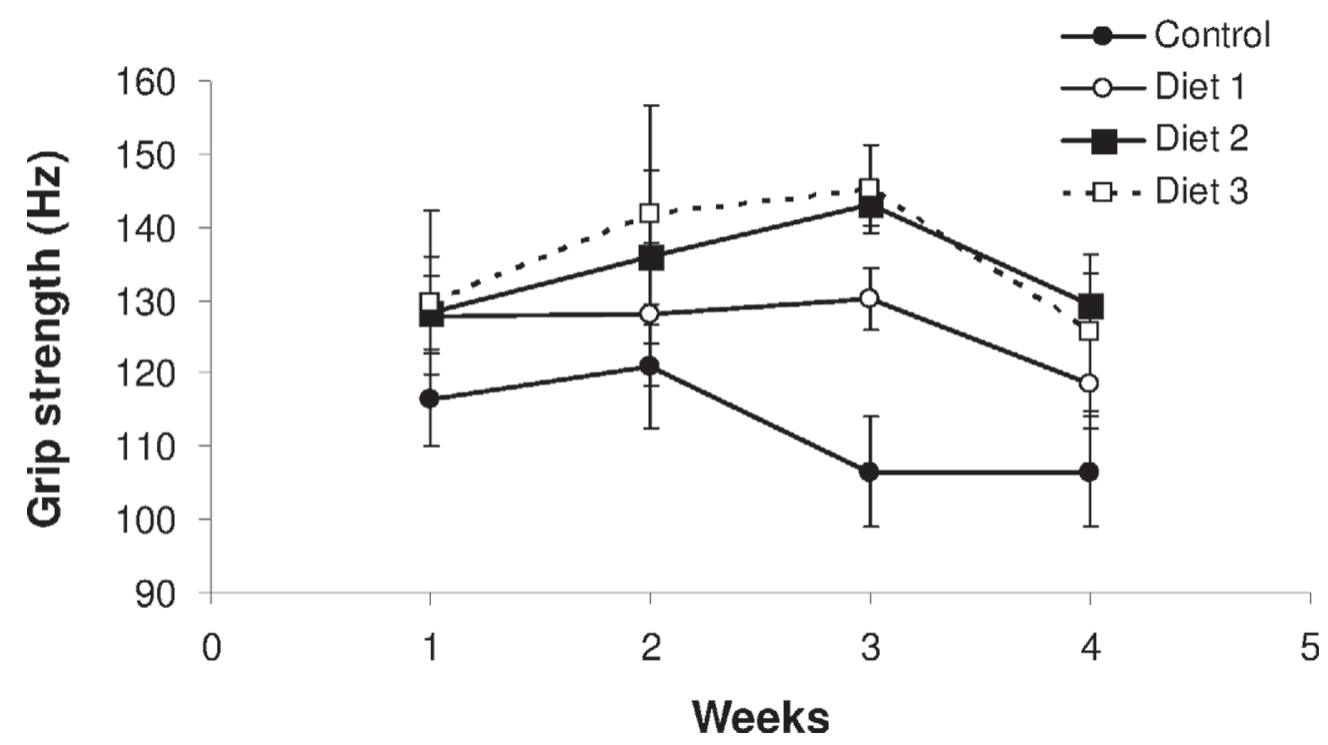

Figure 7. Exercised mice fed RNase5 with $10 \%$ protein content (RNase5-10; i.e., diet 1) and RNase5 with 50\% protein content (RNase5-50) diets (i.e., diets 2 and 3 ) in particular had increased grip strength compared with control mice. The statistically significant effects were observed for both RNase5-50 diets (ANOVA: $P<0.001$ ) and the RNase5-10 diet (ANOVA: $P<0.05$ ). Error bars represent the standard error of the mean for each diet at wk $1,2,3$, and 4 . 
that the RNase5 preparations were biologically active and contained angiogenic activity. The biologically active RNase5 purified from milk was also shown to induce the myogenic differentiation of cultured $\mathrm{C} 2 \mathrm{C} 12$ myoblasts, thus identifying novel growth factor response for RNase5 on cultured muscle cells.

The intracellular actions of RNase5 on skeletal muscle are subject to ongoing experimentation; however, in other cell types, RNase5 is important for protein synthesis, directly stimulating ribosomal RNA synthesis in the nucleolus (Moroianu and Riordan, 1994; Belford et al., 1995). In endothelial and epithelial cell growth, RNase5 is required for the activity of growth factors such as FGF and endothelial growth factor (Kishimoto et al., 2005; Gao and $\mathrm{Xu}, 2008$ ). In endothelial cells, RNase5 binds to cell surface actin (Hu et al., 1993) and is endocytosed by a process involving transient phosphorylation of extracellular signal-related signal kinase 1/2 (ERK1/2; Liu et al., 2001). Ribonuclease 5 is translocated to the nucleolus (Moroianu and Riordan, 1994; Hu, 1998) and upregulates transcription (Xu et al., 2002; Tsuji et al., 2005; Ibaragi et al., 2009) and endothelial nitric oxide synthase activity via phosphatidylinositide 3-kinase and protein kinase B (Akt) signaling (Trouillon et al., 2010).

To ascertain whether milk-derived RNase5 preparations were orally active and had the ability to increase muscle mass in vivo, adult mice were fed known amounts of milk whey protein preparations enriched for RNase 5 . The principal outcome of these experiments was that all 3 experimental diets increased grip strength in exercised mice, indicating improved neuromuscular function. Once mice reach their maximum size in adulthood the bones have fused and muscles no longer increase in length, but in response to hypertrophic stimuli such as exercise or growth factors, muscles can increase in width. Therefore, we would predict that the exercised cohort of mice would be likely to respond and benefit from the diet supplements and record induced muscle growth. Indeed we observed that mice on diets 1 and 2 had heavier quadriceps muscles than mice fed the control for 1 mo.

Lacking a hypertrophic stimulus, sedentary adult mice were not expected to exhibit muscle hypertrophy. Therefore, it was a surprising result that sedentary adult mice fed diet 2 for 4 mo recorded increases in quadriceps muscle weights. We cannot exclude the possibility that the contaminating whey proteins present in the RNase5 preparations contributed to this effect. It is possible that degradation of the whey protein by the digestive system would produce hydrolyzed whey, which has been shown to have a positive effect on muscle strength and weight gain (Cribb et al., 2006). However, the current study required physical activity or exercise for this to occur. Thus, it is difficult to conclude whether the response was specifically due to intact RNase5 directly stimulating muscle growth as observed in vitro or due to whey protein being present in the RNase 5 preparations.

In this study, we did not observe a universal increase in muscle weight, as one might expect. Nonetheless, this observation was similar to other studies within the literature that report that all muscles do not respond to a stimulus in the same manner. For example, previous studies have shown that quadriceps but not TA and gastrocnemius increased muscle weight after voluntary exercise (Leiter et al., 2012). Conversely, we did observe positive effects of the RNase5 diets on grip strength of the forelimb muscles, indicating that the RNase5 diets influenced more than quadriceps weight.

In summary, these data show that RNase5 can be purified from bovine milk whey in significant concentrations while preserving biological activity. This paper also describes the novel role of RNase 5 in muscle development by increasing muscle fiber growth. In adult mice, milk-derived RNase5 preparations increased neuromuscular function and sedentary and exerciseinduced muscle growth.

\section{ACKNOWLEDGMENTS}

The authors thank the Department of Environment and Primary Industries (Melbourne VIC, Australia) and Murray Goulburn Co-operative Co. Ltd. (Brunswick, VIC Australia) for funding this work, Michelle Rowney (Bulla Dairy Foods, Victoria, Australia) for advice and providing RNase5 materials, and Felicity Waters and Hannah Radley-Crabb for conducting the animal experiments at the University of Western Australia (Perth, Australia) and valuable comments in preparing the manuscript.

\section{REFERENCES}

Abernethy, G., D. Otter, K. Arnold, J. Austad, S. Christiansen, I. Ferreira, F. Irvine, C. Marsh, L. R. Massom, K. Pearce, J. Stevens, J. Szpylka, P. Vyas, D. Woollard, and C. Wu. 2010. Determination of immunoglobulin $\mathrm{G}$ in bovine colostrum and milk powders, and in dietary supplements of bovine origin by protein $\mathrm{G}$ affinity liquid chromatography: collaborative study. J. AOAC Int. 93:622-627.

Anderson, K., and D. G. Behm. 2005. The impact of instability resistance training on balance and stability. Sports Med. 35:43-53.

Belford, D. A., M.-L. Rogers, G. O. Regester, G. L. Francis, G. W. Smithers, I. J. Liepe, I. K. Priebe, and F. J. Ballard. 1995. Milkderived growth factors as serum supplements for the growth of fibroblast and epithelial cells. In Vitro Cell. Dev. Biol. Anim. $31: 752-760$.

Bond, M. D., and D. J. Strydom. 1989. Amino acid sequence of bovine angiogenin. Biochemistry 28:6110-6113.

Brown, A., M. Rowney, P. Hobman, M. B. McDonagh, A. Tester, and B. Cocks, inventors. 2010. Process for the preparation of angiogenin using a cation exchange resin. Agriculture Victoria Services 
Pty. Ltd. and Murray Goulburn Co-operative Co. Ltd., assignees. US Pat. No. US20100136172 A1.

Burke, D. G., P. D. Chilibeck, K. S. Davidson, D. G. Candow, J. Farthing, and T. Smith-Palmer. 2001. The effect of whey protein supplementation with and without creatine monohydrate combined with resistance training on lean tissue mass and muscle strength. Int. J. Sport Nutr. Exerc. Metab. 11:349-364.

Burrin, D. G., T. A. Davis, S. Ebner, P. A. Schoknecht, M. L. Fiorotto, and P. J. Reeds. 1997. Colostrum enhances the nutritional stimulation of vital organ protein synthesis in neonatal pigs. J. Nutr. 127:1284-1289.

Burrin, D. G., R. J. Shulman, P. J. Reeds, T. A. Davis, and K. R. Gravitt. 1992. Porcine colostrum and milk stimulate visceral organ and skeletal muscle protein synthesis in neonatal piglets. J. Nutr. 122:1205-1213.

Cribb, P. J., A. D. Williams, M. F. Carey, and A. Hayes. 2006. The effect of whey isolate and resistance training on strength, body composition, and plasma glutamine. Int. J. Sport Nutr. Exerc. Metab. 16:494-509.

D'Auria, E., C. Agostoni, M. Giovannini, E. Riva, R. Zetterström, R. Fortin, G. F. Greppi, L. Bonizzi, and P. Roncada. 2005. Proteomic evaluation of milk from different mammalian species as a substitute for breast milk. Acta Paediatr. 94:1708-1713.

Dyer, A. R., G. A. Burdock, I. G. Carabin, M. C. Haas, J. Boyce, R. Alsaker, and L. C. Read. 2008. In vitro and in vivo safety studies of a proprietary whey extract. Food Chem. Toxicol. 46:1659-1665.

Fett, J. W., D. J. Strydom, R. R. Lobb, E. M. Alderman, J. L. Bethune, J. F. Riordan, and B. L. Vallee. 1985. Isolation and characterization of angiogenin, an angiogenic protein from human carcinoma cells. Biochemistry 24:5480-5486.

Fiorotto, M. L., T. A. Davis, P. J. Reeds, and D. G. Burrin. 2000. Nonnutritive factors in colostrum enhance myofibrillar protein synthesis in the newborn pig. Pediatr. Res. 48:511-517.

Gao, X., and Z. Xu. 2008. Mechanisms of action of angiogenin. Acta Biochim. Biophys. Sin. (Shanghai) 40:619-624.

Hodgetts, S., H. Radley, M. Davies, and M. D. Grounds. 2006. Reduced necrosis of dystrophic muscle by depletion of host neutrophils, or blocking TNF $\alpha$ function with etanercept in $\mathrm{mdx}$ mice. Neuromuscul. Disord. 16:591-602.

Hu, G. F. 1998. Neomycin inhibits angiogenin-induced angiogenesis. Proc. Natl. Acad. Sci. USA 95:9791-9795.

Hu, G. F., D. J. Strydom, J. W. Fett, J. F. Riordan, and B. L. Vallee. 1993. Actin is a binding protein for angiogenin. Proc. Natl. Acad. Sci. USA 90:1217-1221.

Ibaragi, S., N. Yoshioka, H. Kishikawa, J. K. Hu, P. M. Sadow, M. $\mathrm{Li}$, and G. Hu. 2009. Angiogenin-stimulated rRNA transcription is essential for initiation and survival of AKT-induced prostate intraepithelial neoplasia. Mol. Cancer Res. 7:415-424.

Kishimoto, K., S. Liu, T. Tsuji, K. A. Olson, and G. Hu. 2005. Endogenous angiogenin in endothelial cells is a general requirement for cell proliferation and angiogenesis. Oncogene 24:445-456.

Kussendrager, K. D., and A. C. van Hooijdonk. 2000. Lactoperoxidase: Physico-chemical properties, occurrence, mechanism of action and applications. Br. J. Nutr. 84(Suppl. 1):S19-S25.

Laemmli, U. K. 1970. Cleavage of structural proteins during the assembly of the head of bacteriophage T4. Nature 227:680-685.

Leiter, J. R. S., R. Upadhaya, and J. E. Anderson. 2012. Nitric oxide and voluntary exercise together promote quadriceps hypertrophy and increase vascular density in female 18-mo-old mice. Am. J. Physiol. Cell Physiol. 302:C1306-C1315.

Liu, S., D. Yu, Z. P. Xu, J. F. Riordan, and G. F. Hu. 2001. Angiogenin activates Erk1/2 in human umbilical vein endothelial cells. Biochem. Biophys. Res. Commun. 287:305-310.
Moroianu, J., and J. F. Riordan. 1994. Nuclear translocation of angiogenin in proliferating endothelial cells is essential to its angiogenic activity. Proc. Natl. Acad. Sci. USA 91:1677-1681.

Olsen, S., P. Aagaard, F. Kadi, G. Tufekovic, J. Verney, J. L. Olesen, C. Suetta, and M. Kjær. 2006. Creatine supplementation augments the increase in satellite cell and myonuclei number in human skeletal muscle induced by strength training. J. Physiol. 573:525-534.

Pennings, B., Y. Boirie, J. M. G. Senden, A. P. Gijsen, H. Kuipers, and L. J. C. van Loon. 2011. Whey protein stimulates postprandial muscle protein accretion more effectively than do casein and casein hydrolysate in older men. Am. J. Clin. Nutr. 93:997-1005.

Phillips, S. M., J. E. Tang, and D. R. Moore. 2009. The role of milkand soy-based protein in support of muscle protein synthesis and muscle protein accretion in young and elderly persons. J. Am. Coll. Nutr. 28:343-354.

Ponce, M. L. 2001. In vitro Matrigel angiogenesis assays. Methods Mol. Med. 46:205-209.

Pouliot, Y., and S. F. Gauthier. 2006. Milk growth factors as health products: Some technological aspects. Int. Dairy J. 16:1415-1420.

Radley, H. G., M. J. Davies, and M. D. Grounds. 2008. Reduced muscle necrosis and long-term benefits in dystrophic mdx mice after cV1q (blockade of TNF) treatment. Neuromuscul. Disord. 18:227-238.

Radley, H. G., and M. D. Grounds. 2006. Cromolyn administration (to block mast cell degranulation) reduces necrosis of dystrophic muscle in mdx mice. Neurobiol. Dis. 23:387-397.

Radley-Crabb, H., J. Terrill, T. Shavlakadze, J. Tonkin, P. Arthur, and M. Grounds. 2012. A single 30 min treadmill exercise session is suitable for 'proof-of concept studies' in adult mdx mice: A comparison of the early consequences of two different treadmill protocols. Neuromuscul. Disord. 22:170-182.

Reeves, P. G., F. H. Nielsen, and G. C. Fahey Jr. 1993. AIN-93 purified diets for laboratory rodents: Final report of the American Institute of Nutrition ad hoc writing committee on the reformulation of the AIN-76A rodent diet. J. Nutr. 123:1939-1951.

Rogers, M. L., D. A. Belford, G. L. Francis, and F. J. Ballard. 1995. Identification of fibroblast growth factors in bovine cheese whey. J. Dairy Res. 62:501-507.

Rogers, M. L., C. Goddard, G. O. Regester, F. J. Ballard, and D. A. Belford. 1996. Transforming growth factor $\beta$ in bovine milk: Concentration, stability and molecular mass forms. J. Endocrinol. 151:77-86.

Tipton, K. D., T. A. Elliott, M. G. Cree, A. A. Aarsland, A. P. Sanford, and R. R. Wolfe. 2007. Stimulation of net muscle protein synthesis by whey protein ingestion before and after exercise. Am. J. Physiol. Endocrinol. Metab. 292:E71-E76.

Trouillon, R., D.-K. Kang, H. Park, S.-I. Chang, and D. O'Hare. 2010. Angiogenin induces nitric oxide synthesis in endothelial cells through PI-3 and Akt kinases. Biochemistry 49:3282-3288.

Tsuji, T., Y. Sun, K. Kishimoto, K. A. Olson, S. Liu, S. Hirukawa, and G. F. Hu. 2005. Angiogenin is translocated to the nucleus of HeLa cells and is involved in ribosomal RNA transcription and cell proliferation. Cancer Res. 65:1352-1360.

Xu, Z., T. Tsuji, J. F. Riordan, and G. Hu. 2002. The nuclear function of angiogenin in endothelial cells is related to rRNA production. Biochem. Biophys. Res. Commun. 294:287-292.

Yaffe, D., and O. Saxel. 1977. Serial passaging and differentiation of myogenic cells isolated from dystrophic mouse muscle. Nature 270:725-727. 